\title{
Syntheses and Properties of Cerium Diphthalocyanines in High Oxidation States; Crystal Structure of $\left[\mathrm{Ce}(\mathrm{Pc})_{2}\right]\left(\mathrm{BF}_{4}\right)_{0.33}$
}

\author{
G. Ostendorp ${ }^{\mathrm{a}}$, H. W. Rotter ${ }^{\mathrm{b}}, \mathrm{H}$. Homborg ${ }^{\mathrm{a}, *}$
}

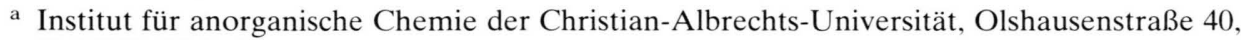
D-24098 Kiel, Germany

b Institut für Analytische und Anorganische Chemie und Materialforschungszentrum der Albert-Ludwigs-Universität, Albertstraße 21, D-12345 Freiburg, Germany

Z. Naturforsch. 51 b, 567-573 (1996); received September 14, 1995

Diphthalocyanines, Cerium Compounds, Crystal Structure, UV-VIS-NIR Spectra,

Vibrational Spectra

Ring oxidized green Cerium(IV)diphthalocyanines, $\left[\mathrm{Ce}(\mathrm{Pc})_{2}\right] \mathrm{X}\left(\mathrm{X}=\right.$ (poly)halide, $\left.\mathrm{NO}_{3}{ }^{-}\right)$ are prepared by chemical oxidation of $\left({ }^{n} \mathrm{Bu}_{4} \mathrm{~N}\right)\left[\mathrm{Ce}\left(\mathrm{Pc}^{2-}\right)_{2}\right]$ with the corresponding halogen in solution or of solid $\left[\mathrm{Ce}\left(\mathrm{Pc}^{2-}\right)_{2}\right]$ with aqueous $\mathrm{HNO}_{3}$. Electrochemical oxidation of $\left({ }^{n} \mathrm{Bu}_{4} \mathrm{~N}\right)\left[\mathrm{Ce}\left(\mathrm{Pc}^{2-}\right)_{2}\right]$ in solution in the presence of $\left({ }^{n} \mathrm{Bu}_{4} \mathrm{~N}\right) \mathrm{BF}_{4}$ yields $\left[\mathrm{Ce}(\mathrm{Pc})_{2}\right]\left(\mathrm{BF}_{4}\right)_{0.33}$, which crystallizes in the tetragonal space group $\mathrm{P} 4 / \mathrm{nnc}(a, b=19.643(3) \AA, c=6.525(3) \AA$, $\mathrm{Z}=2)$. The $\mathrm{Ce}^{\mathrm{IV}}$ ion is eightfold coordinated by the isoindole $\mathrm{N}$ atoms $\left(\mathrm{N}_{\text {iso }}\right)$ of the two staggered $\left(\mathrm{ca} \cdot 41^{\circ}\right)$, slightly distorted $\mathrm{Pc}$ ligands. The "[Ce( $\left.\left.\mathrm{Pc}\right)_{2}\right]^{0.33+"}$ subunits are arranged in infinite columns along [001] with the Ce atoms statistically disordered over two positions and $\mathrm{Ce}-\mathrm{N}_{\text {iso }}$ bond lengths of 2.45(1) and 2.69(1) $\AA$, respectively. The UV-VIS spectrum is dominated by the transitions of the $\mathrm{Pc}^{2-}$ ligand at $c a$. 15,000 (B band), 30,000 and 36,000 $\mathrm{cm}^{-1}$ (Q, N region). A low energy ("metallic") band at $c a .2800 \mathrm{~cm}^{-1}$ typical for partially oxidized systems is present. The UV-VIS-NIR spectrum of $\left[\mathrm{Ce}(\mathrm{Pc})_{2}\right] \mathrm{NO}_{3}$ indicates a cofacial $\mathrm{Pc}^{2-}-\mathrm{Pc}^{-}$complex. In addition to the $\pi-\pi$ ' transitions of the $\mathrm{Pc}^{2-}$ moiety at $c a .14,000,30,000$ and $36,000 \mathrm{~cm}^{-1}$, the $\mathrm{Q}_{1}$ transition of the $\mathrm{Pc}^{-}$ring is observed at $c a .19,200 \mathrm{~cm}^{-1}$ and the typical NIR band at $6380 \mathrm{~cm}^{-1}$. Oxidation of a thin film of (PNP) $\left[\mathrm{Ce}\left(\mathrm{Pc}^{2-}\right)_{2}\right]$ with dry $\mathrm{Br}_{2} /$ $\mathrm{N}_{2}$ gas yields purple [Ce( $\left.\left(\mathrm{Pc}^{-}\right)_{2}\right] \mathrm{Br}_{x}$, whose UV-VIS-NIR spectrum shows the diagnostic features of dimeric $\mathrm{Pc}^{-}$radicals with intense bands at $c a .14,000$ and $18,000 \mathrm{~cm}^{-1}$ assigned as $\mathrm{B}$ and $\mathrm{Q}_{1}$ bands, respectively. At $c a .9000 \mathrm{~cm}^{-1}$ the typical $\mathrm{Q}_{\mathrm{D}}$ absorption is observed. The vibrational spectra are dominated by the transitions of the $\mathrm{Pc}^{-}$ligand at $1305 / 1445 \mathrm{~cm}^{-1}$ (IR) and 560/1120/1172/1591 $\mathrm{cm}^{-1}$ (resonance Raman). Excitation with $1064 \mathrm{~nm}$ strongly enhances the sym. $\mathrm{Ce}-\mathrm{N}$ stretch at $163 \mathrm{~cm}^{-1}$.

\section{Introduction}

In the last twenty years metallodiphthalocyanines, especially those of the lanthanides $\left(\left[\operatorname{Ln}(\mathrm{Pc})_{2}\right]\right)$, have been investigated intensively because of their (semi)conducting [1,2] and electrochromic $[3,4]$ properties. Within the lanthanide series cerium keeps an exceptional position as there is a low lying redox couple $\mathrm{Ce}^{3+} / \mathrm{Ce}^{4+}$, and it has been shown that the one electron oxidation of $\left({ }^{n} \mathrm{Bu}_{4} \mathrm{~N}\right)\left[\mathrm{Ce}^{\mathrm{III}}\left(\mathrm{Pc}^{2-}\right)_{2}\right]\left(\left({ }^{n} \mathrm{Bu}_{4} \mathrm{~N}\right)\right.$ : tetra- $n$ butylammonium) yields $\left[\mathrm{Ce}^{\mathrm{IV}}\left(\mathrm{Pc}^{2-}\right)_{2}\right]$ [5]. On the other hand small singlet-triplet splittings and a possible Kondo analogue behaviour is predicted for cerium diphthalocyanine $[6,7]$. This type of a partially oxidized radical species " $\left[\mathrm{Ln}^{\mathrm{III}}\left(\mathrm{Pc}^{2-}\right)\left(\mathrm{Pc}^{-}\right)\right]$" is typically formed by the one-electron oxidation of the

\footnotetext{
* Reprint requests to Dr. H. Homborg.
}

complex salts of the other lanthanides $[8,9]$. An analogous di(porphyrinato)cerium(IV) compound, containing the " $\left[\mathrm{Ce}^{\mathrm{IV}}\left(\mathrm{Por}^{2-}\right)\left(\mathrm{Por}^{-}\right)\right]^{+}$" radical ion, is well known [10-12]. No reports have so far been given to our knowledge on oxidized di(phthalocyaninato)cerium complexes. In the present paper we describe the preparation and properties of the complexes $\left[\mathrm{Ce}(\mathrm{Pc})_{2}\right]\left(\mathrm{BF}_{4}\right)_{0.33}$, $\left[\mathrm{Ce}(\mathrm{Pc})_{2}\right]\left(\mathrm{NO}_{3}\right),\left[\mathrm{Ce}(\mathrm{Pc})_{2}\right] \mathrm{Cl}_{3.5}$ and $\left[\mathrm{Ce}(\mathrm{Pc})_{2}\right] \mathrm{Br}_{2.7}$.

\section{Experimental Section}

$\left({ }^{n} \mathrm{Bu}_{4} \mathrm{~N}\right)\left[\mathrm{Ce}\left(\mathrm{Pc}^{2-}\right)_{2}\right] \quad\left({ }^{n} \mathrm{Bu}_{4} \mathrm{~N}:\right.$ Tetra- $n$-butylammonium), (PNP) $\left[\mathrm{Ce}\left(\mathrm{Pc}^{2-}\right)_{2}\right]$ (PNP: Bis(triphenylphosphine)iminium) and $\left[\mathrm{Ce}\left(\mathrm{Pc}^{2-}\right)_{2}\right]$ were prepared as described previously $[5,13]$.

\section{Synthesis of $\left[\mathrm{Ce}\left(\mathrm{Pc}_{2}\right]\left(\mathrm{BF}_{4}\right)_{0.33}\right.$}

A concentrated solution of $\left({ }^{n} \mathrm{Bu}_{4} \mathrm{~N}\right)\left[\mathrm{Ce}\left(\mathrm{Pc}^{2-}\right)_{2}\right]$ in dichloromethane was oxidized electrochemi- 
cally in the presene of $\left({ }^{n} \mathrm{Bu}_{4} \mathrm{~N}\right)\left(\mathrm{BF}_{4}\right)$ as supporting electrolyte. After several days black needles of $\left[\mathrm{Ce}(\mathrm{Pc})_{2}\right]\left(\mathrm{BF}_{4}\right)_{0.33}$ grew at the $\mathrm{Pt}$ anode. The solution was filtered off, and the precipitate washed several times with dichloromethane.

\section{Synthesis of $\left[\mathrm{Ce}(\mathrm{Pc})_{2}\right]\left(\mathrm{NO}_{3}\right)$}

Finely powdered $\left[\mathrm{Ce}(\mathrm{Pc})_{2}\right]$ was stirred in aqueous $\mathrm{HNO}_{3}(20 \%)$ for $30 \mathrm{~min}$ at room temperature. With progressing reaction the colour of the solid changed from blue-purple to dark green. $\left[\mathrm{Ce}(\mathrm{Pc})_{2}\right]\left(\mathrm{NO}_{3}\right)$ was separated, washed with cold water, and dried in vacuo.

\section{Synthesis of $\left[\mathrm{Ce}(\mathrm{Pc})_{2}\right] \mathrm{Br}_{2.7}$ and $\left[\mathrm{Ce}(\mathrm{Pc})_{2}\right] \mathrm{Cl}_{3.5}$}

$100 \mathrm{mg}$ of $\left({ }^{n} \mathrm{Bu}_{4} \mathrm{~N}\right)\left[\mathrm{Ce}\left(\mathrm{Pc}^{2-}\right)_{2}\right]$ was dissolved in $50 \mathrm{ml}$ of dry dichloromethane and bromine or chlorine was added in excess. The mixture was stirred for $15 \mathrm{~min}$ to complete the oxidation. Black-green $\left[\mathrm{Ce}(\mathrm{Pc})_{2}\right] \mathrm{Br}_{2.7}$ or $\left[\mathrm{Ce}(\mathrm{Pc})_{2}\right] \mathrm{Cl}_{3.5}$ precipitated. The solid was collected, washed with dry dichloromethane and dried in vacuo. The composition of the complex salts is not reproducible due to variable amounts of halogen incorporated.

All complex-salts gave satisfactory elemental analysis [14].

\section{Instrumentation}

CHN analysis: Heraeus CHN-Rapid-Elementaranalysator.

$\mathrm{Cl}, \mathrm{Br}$ analysis: After combustion potentiometrically with $\mathrm{Ag}^{+}$.

Difference pulse polarography and cyclic voltammetry: Polarecord 626 and VA-Scanner 612 (Metrohm). Reference electrode: $\mathrm{Ag} / \mathrm{AgCl}(0.1 \mathrm{M}$ $\left.\mathrm{LiCl} / \mathrm{C}_{2} \mathrm{H}_{5} \mathrm{OH}\right)$, working and auxiliary electrode: $\mathrm{Pt}$ bead and $\mathrm{Pt}$ wire. Supporting electrolyte: $0.1 \mathrm{M}$ $\left({ }^{n} \mathrm{Bu}_{4} \mathrm{~N}\right) \mathrm{ClO}_{4}$ in dry dichloromethane. All measurements were carried out at $-25{ }^{\circ} \mathrm{C}$ under a stream of nitrogen. Scan speed: $10 \mathrm{mV} / \mathrm{s}$ (DPP); 30 $\mathrm{mV} / \mathrm{s}(\mathrm{CV})$.

$U V$-VIS-NIR spectra: Varian spectrophotometer Cary $5 ; \mathrm{KBr}$ pellets or thin films on a $\mathrm{CaF}_{2}$ disk; range: $200-3300 \mathrm{~nm}$.

MIR spectra: ATI Mattson FT-IR interferometer model Genesis; KBr pellets.

FIR spectra: Bruker FT-IR interferometer IFS $66 \mathrm{CS}$; polyethylene pellets.

Raman spectra: Instruments $\mathrm{SA}$ spectrometer $\mathrm{U}$ 1000 or Dilor multichannel spectrometer XY; $\mathrm{KBr}$ pellets, $10 \mathrm{~K}$ or $80 \mathrm{~K}$. Excitation with $\mathrm{Ar}^{+}$and $\mathrm{Kr}^{+}$ lasers (Spectra Physics, model 2025 and 171).

FT-Raman spectra: Bruker interferometer IFS 66 with FRA 106 Raman equipment. Excitation with a NDYAG laser (Adlas).

Crystal structure determination: Details of data collection and crystal structure refinement of $\alpha$ $\left[\mathrm{Ce}(\mathrm{Pc})_{2}\right]\left(\mathrm{BF}_{4}\right)_{0.33}$ are given in Table I. Cell parameters and space group were determined by Weissenberg and procession methods. Intensities were collected on an Enraf-Nonius CAD 4 diffractometer at $293 \mathrm{~K}$. No absorption correction was applied. The structure determination and refinement were performed with the programs SHELX86 and SHELXL92 [15,16]. The occupancy coefficients of the $\mathrm{Ce}$ and the boron atom were refined with fixed isotropic temperature factors. In a last step these isotropic temperature factors were refined with fixed occupancy coefficients. Only the $\mathrm{C}$ and $\mathrm{N}$ atoms were refined anisotropically. The hydrogen atoms were located at calculated positions. The $\left[\mathrm{BF}_{4}\right]^{-}$ion is rotationally disordered; therefore fluorine atoms could not be located. Atomic coordinates, equivalent isotropic temperature factors for non-hydrogen atoms, listings of anisotropic thermal parameters and a complete list of bond distances and angles have been deposited as supplementary material [17]. Figures 2 and 3 were drawn with an ORTEPII program [18].

Table I. Crystal data and structure refinement for $\left[\mathrm{Ce}(\mathrm{Pc})_{2}\right]\left(\mathrm{BF}_{4}\right)_{0.33}$.

\begin{tabular}{ll}
\hline Formula & $\mathrm{C}_{64} \mathrm{H}_{32} \mathrm{~B}_{0.33} \mathrm{CeF}_{1.32} \mathrm{~N}_{16}$ \\
Formula Weight & 1194.1 \\
$a(\AA)$ & $19.643(3)$ \\
$b(\AA)$ & $19.643(3)$ \\
$c(\AA)$ & $6.525(3)$ \\
$\mathrm{V}\left(\AA^{3}\right)$ & $2517(2)$ \\
$\mathrm{Z}$ & 2 \\
$\mathrm{D}_{\text {cal }}\left(\mathrm{g} \cdot \mathrm{cm}^{-3}\right)$ & 1.567 \\
Crystal System & tetragonal \\
Space Group & $\mathrm{P} 4 / \mathrm{nnc}(\mathrm{No} .126)$ \\
$h, k, l$ & $\pm 23,+23,-7$ \\
Radiation $(\AA)$ & $\mathrm{MoK} \alpha, \lambda=0.71069$ \\
Scan Mode & $\omega / 2 \theta$ \\
$\theta($ min, max $)$ & $2.93,24.98$ \\
Data collected & 4268 \\
Independent data & 1117 \\
Data obs. [(I $>4 \sigma(\mathrm{I}))]$ & 642 \\
Parameter & 98 \\
$\mu\left(\mathrm{cm}^{-1}\right)$ & 0.98 \\
$R 1[(\mathrm{I}>4 \sigma(\mathrm{I}))]$ & 0.052 \\
$w R 2($ all data) & 0.232 \\
$\Delta \varrho$ max/min $\left(\mathrm{e} \mathrm{A} \mathrm{A}^{-3}\right)$ & $0.77 /-0.81$ \\
\hline
\end{tabular}

Formula

Formula Weight

$a(\AA)$

(

$\mathrm{V}\left(\AA^{3}\right)$

Space Group

$h, k, l$

Radiation (A)

$\theta$ (min, max

Data collected

Independent data

政 $>4 \sigma(\mathrm{I}))]$

$\left(\mathrm{cm}^{-1}\right)$

$R 1[(\mathrm{I}>4 \sigma(\mathrm{I}))]$

$\Delta \varrho_{\max / \min }\left(\mathrm{e} \mathrm{A}^{-3}\right)$ 


\section{Results and Discussion}

\section{Synthesis and properties}

The difference pulse polarogram (Fig. 1) of a solution of $\left({ }^{n} \mathrm{Bu}_{4} \mathrm{~N}\right)\left[\mathrm{Ce}\left(\mathrm{Pc}^{2-}\right)_{2}\right]$ in dichloromethane shows five distinct current peaks representing quasi-reversible single electron electrode processes. The two current peaks in the cathodic range are related to the successive first one-electron reduction of the two $\mathrm{Pc}$ ligands $\left(\mathrm{E}_{\mathrm{red}}(\mathrm{I})=\right.$ $-1,10 \mathrm{~V} ;\left[\mathrm{Ce}\left(\mathrm{Pc}^{2-}\right)_{2}\right]^{-/}\left[\mathrm{CePc}^{2-} \mathrm{Pc}^{3-}\right]^{2-} ; \mathrm{E}_{\mathrm{red}}(\mathrm{II})=$ $-1,32 \mathrm{~V} ;\left[\mathrm{CePc}^{2-} \mathrm{Pc}^{3-}\right]^{2-} /\left[\mathrm{Ce}\left(\mathrm{Pc}^{3-}\right)_{2}\right]^{3-}$; for a better understanding all redox couples are given in the formalism of localized states). The first anodic current peak at $\mathrm{E}_{\mathrm{ox}}=0.07 \mathrm{~V}$ is metal centered: $\left[\mathrm{Ce}^{\mathrm{III}}\left(\mathrm{Pc}^{2-}\right)_{2}\right]^{-} /\left[\mathrm{Ce}^{\mathrm{IV}}\left(\mathrm{Pc}^{2-}\right)_{2}\right]$, while the second anodic current peak at $\mathrm{E}_{\mathrm{ox}}(\mathrm{I})=0.60 \mathrm{~V}$ is related to the oxidation of one of the $\mathrm{Pc}$ ligands $\left(\left[\mathrm{Ce}\left(\mathrm{Pc}^{2-}\right)_{2}\right] /\left[\mathrm{Ce}\left(\mathrm{Pc}^{2-}\right)\left(\mathrm{Pc}^{-}\right)\right]^{+}\right)$. Due to the presence of formally quadrivalent cerium, $\mathrm{E}_{\mathrm{ox}}(\mathrm{I})$ is shifted to higher potential as compared with the neighbouring $\mathrm{Ln}^{\text {III }}$ diphthalocyanines and thus deviates distinctly from the linear relationship found within the series of $\mathrm{Ln}^{\mathrm{III}}$ diphthalocyanines, by which $\mathrm{E}_{\mathrm{ox}}(\mathrm{I})$ increases almost linearly with increasing $\mathrm{Ln}^{\mathrm{III}}$ radius [19]. The shape of this current peak indicates that there is a further not resolved electrode process present, probably originating from $\mathrm{H}\left[\mathrm{Ce}(\mathrm{Pc})_{2}\right]$. The oxidation of the second $\mathrm{Pc}$ ligand $\left(\left[\mathrm{Ce}\left(\mathrm{Pc}^{2-}\right)\left(\mathrm{Pc}^{-}\right)\right]^{+} /\left[\mathrm{Ce}\left(\mathrm{Pc}^{-}\right)_{2}\right]^{2+}\right)$ is observed at $\mathrm{E}_{\mathrm{ox}}(\mathrm{II})=1.07 \mathrm{~V}$, formerly described as an irreversible electrode process in the cyclic voltammogram [5]. These high potentials are in good agreement with data observed for diphthalocyanines of the quadrivalent metal ions of zirconium and hafnium [20].

In accordance with the electrochemical data $\left[\mathrm{Ce}\left(\mathrm{Pc}^{2-}\right)_{2}\right]$ is prepared by anodic oxidation of dis-

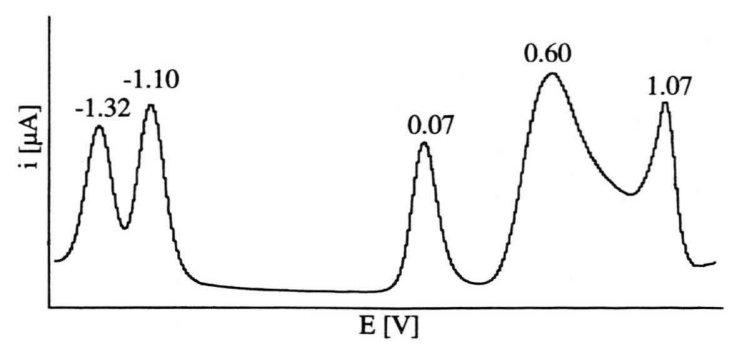

Fig. 1. Difference pulse polarogram of $\left({ }^{n} \mathrm{Bu}_{4} \mathrm{~N}\right)\left[\mathrm{Ce}\left(\mathrm{Pc}^{2-}\right)_{2}\right]$ in $\mathrm{CH}_{2} \mathrm{Cl}_{2} /\left({ }^{n} \mathrm{Bu}_{4} \mathrm{~N}\right) \mathrm{ClO}_{4} ;-1.5 \mathrm{~V}-$ $1,3 \mathrm{~V},-25^{\circ} \mathrm{C}$. solved $\left({ }^{n} \mathrm{Bu}_{4} \mathrm{~N}\right)\left[\mathrm{Ce}\left(\mathrm{Pc}^{2-}\right)_{2}\right]$ at low potential [5]. By electrocrystallization at higher voltage with $\left({ }^{n} \mathrm{Bu}_{4} \mathrm{~N}\right) \mathrm{BF}_{4}$ as supporting electrolyte only the partially oxidized compound $\left[\mathrm{Ce}(\mathrm{Pc})_{2}\right]\left(\mathrm{BF}_{4}\right)_{0.33}$ is formed. Neither $\left[\mathrm{Ce}(\mathrm{Pc})_{2}\right]\left(\mathrm{BF}_{4}\right)$ nor even $\left[\mathrm{Ce}\left(\mathrm{Pc}^{-}\right)_{2}\right]\left(\mathrm{BF}_{4}\right)_{2}$ is obtained by this method. Comparable behaviour has been reported for diphthalocyanines of tervalent rare earth ions, recently [21]. Obviously, this seems to be intrinsic to the electrocrystallization technique favouring the less soluble and most electrical conducting compound to cover the surface of the anode. Independent of the oxidant used $\left(\mathrm{Cl}_{2}, \mathrm{Br}_{2}\right.$ or $\left.\mathrm{HNO}_{3}\right)$, chemical oxidation yields salts of the half-oxidized green $\left[\mathrm{Ce}^{\mathrm{IV}}(\mathrm{Pc})_{2}\right]^{+}$ion. Contrary to the $\mathrm{Ln}^{\mathrm{III}}$ diphthalocyanines the fully oxidized purple diradical $\left[\mathrm{Ce}\left(\mathrm{Pc}^{-}\right)_{2}\right]^{2+}$ is difficult to synthesize and isolate in this manner. On the other hand, treatment of a thin film of blue (PNP) $\left[\mathrm{Ce}\left(\mathrm{Pc}^{2-}\right)_{2}\right]$ on a $\mathrm{CaF}_{2}$ disk with a dry $\mathrm{Br}_{2} / \mathrm{N}_{2}$ gas mixture leads to a purple film characterized by the typical absorption bands of dimeric co-facial phthalocyanine $\pi$-radicals (vide infra). Due to its high oxidation potential, $\left[\mathrm{Ce}\left(\mathrm{Pc}^{-}\right)_{2}\right]^{2+}$ is very sensitive against moisture. To our knowledge the same is true for other quadrivalent diphthalocyanines that have not been isolated as pure dications so far.

\section{Structure of $\alpha$-di(phthalocyaninato)cerium(IV)- tetrafluoroborate, $\alpha-\left[\mathrm{Ce}(\mathrm{Pc})_{2}\right]\left(\mathrm{BF}_{4}\right)_{0.33}$}

The structure of the title compound closely resembles structures reported for partially ring oxidized diphthalocyanines of tervalent rare earth metal ions, e.g. $\alpha-\left[\operatorname{Pr}\left(\mathrm{Pc}_{2}\right)_{3}\right] \mathrm{Br}_{1.5}$ [22], $\alpha$ $\left[\mathrm{Sm}(\mathrm{Pc})_{2}\right] \mathrm{Br}_{1.38}$ and $\alpha-\left[\mathrm{Sm}(\mathrm{Pc})_{2}\right]\left(\mathrm{ClO}_{4}\right)_{0.63} \quad$ [21]. Crystal data and details on data collection and structure solution are given in Table I. Atomic coordinates and (equivalent) isotropic displacement coefficients for the non-hydrogen atoms are given in Table II.

The crystal packing of $\left[\mathrm{Ce}(\mathrm{Pc})_{2}\right]\left(\mathrm{BF}_{4}\right)_{0.33}$ is illustrated in Fig. 2. Infinite columns of the sandwich-like $\left[\mathrm{Ce}(\mathrm{Pc})_{2}\right]^{0.33+}$ subunits along the tetragonal axis represent the quasi-one-dimensional character of the crystal structure. Voids formed by adjacent molecular stacks contain the $\left[\mathrm{BF}_{4}\right]^{-}$ counter ions. A disordered disposition of the $\mathrm{Ce}$ atoms onto two special crystallographic positions $((2 a)$ and $(2 b))$ in the ratio of $1: 6.2$ is found com- 
Table II. Atomic coordinates $\left(\times 10^{4} \AA\right)$ and (equivalent) isotropic displacement coefficients $\left(\AA^{2} \times 10^{3}\right)$ for $\left[\mathrm{Ce}(\mathrm{Pc})_{2}\right]\left(\mathrm{BF}_{4}\right)_{0.33}$. $\mathrm{U}_{\text {eq }}$ is defined as one third of the trace of the orthogonalized $\mathrm{U}_{\mathrm{ij}}$ tensor.

\begin{tabular}{lclll}
\hline Atom & $x$ & $y$ & $z$ & $\mathrm{U}_{\text {eq }}$ \\
\hline Ce1 & 2500 & 2500 & 2500 & $27(1)$ \\
Ce2 & 2500 & 2500 & 7500 & $48(5)$ \\
N1 & $942(4)$ & $1770(4)$ & $58(16)$ & $41(5)$ \\
N2 & $1561(4)$ & $2835(4)$ & $272(14)$ & $40(5)$ \\
C1 & $1364(6)$ & $3511(6)$ & $115(16)$ & $41(8)$ \\
C2 & $201(6)$ & $4100(7)$ & $-119(21)$ & $61(7)$ \\
C3 & $-481(6)$ & $3960(8)$ & $-272(25)$ & $84(7)$ \\
C4 & $-723(7)$ & $3291(9)$ & $-226(25)$ & $84(8)$ \\
C5 & $-291(6)$ & $2737(7)$ & $-111(22)$ & $69(6)$ \\
C6 & $984(4)$ & $2444(8)$ & $117(15)$ & $39(4)$ \\
C7 & $627(5)$ & $3549(6)$ & $-61(18)$ & $45(6)$ \\
C8 & $398(5)$ & $2881(6)$ & $-32(18)$ & $46(6)$ \\
B & 7500 & 2500 & 7500 & $75(44)$ \\
\hline
\end{tabular}

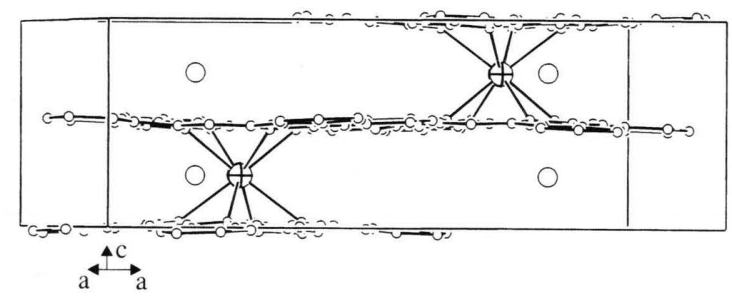

Fig. 2. View of the crystal packing of $\left[\mathrm{Ce}(\mathrm{Pc})_{2}\right]\left(\mathrm{BF}_{4}\right)_{0.33}$. $\mathrm{H}$ atoms omitted for clarity.

parable to situation in the Pr and Sm compounds mentioned. The present structure differs by the ordered disposition of the anions. In accordance with the elementary analysis, the refinement of the occupancy coefficient for the boron atoms yields the stoichiometric composition $\left[\mathrm{Ce}(\mathrm{Pc})_{2}\right]\left(\mathrm{BF}_{4}\right)_{0.33}$. Thus the Pc ligands are partially oxidized and in a localized view the solid phase can be described as $2\left[\mathrm{Ce}\left(\mathrm{Pc}^{2-}\right)_{2}\right]_{2} \cdot\left[\mathrm{Ce}\left(\mathrm{Pc}^{2-}\right)\left(\mathrm{Pc}^{-}\right)\right]\left(\mathrm{BF}_{4}\right)$. In fact, all Pc ligands in this highly symmetrical structure are equal due to symmetry requirements; no distinction between the dianionic $\mathrm{Pc}^{2-}$ and the monoanionic radical $\mathrm{Pc}^{-}$can be made. This is in agreement with the diamagnetism of the compound indicating strong spin-spin coupling within the columns. The $\mathrm{Ce}$ atom is coordinated by the eight isoindole nitrogen atoms $\left(\mathrm{N} 2=\mathrm{N}_{\text {iso }}\right)$ of the two staggered $\left(41^{\circ}\right)$ macrocycles forming a distorted square antiprism. The $(\mathrm{N} 2)_{4}$ planes are separated by 2.908 and $3.616 \AA$ intra- und interplane distances, alternatively. Correspondingly the $\mathrm{Ce}-\mathrm{N} 2$ bond dis- tance is 2.45(1) for $\mathrm{Ce} 1$ and 2.67(1) $\AA$ for $\mathrm{Ce} 2$. The Pc rings are significantly distorted from planarity. As evidenced by the vertical displacement of the outermost carbon atoms C3 $(0.365 \AA)$ and C $4(0.312 \AA)$ from the $(\mathrm{N} 2)_{4}$ plane, this distortion is smaller in $\alpha$ - $\left[\mathrm{Ce}(\mathrm{Pc})_{2}\right]\left(\mathrm{BF}_{4}\right)_{0.33}$ than in other diphthalocyanines of quadrivalent metals such as Sn $(1.09 \AA)$ [23], Zr (1.47 $)$ [24] or Ti $(0.64 \AA)$ [25]. All inner bond length and angles (Fig. 3) of the macrocycle compare closely with other metallophthalocyanines.

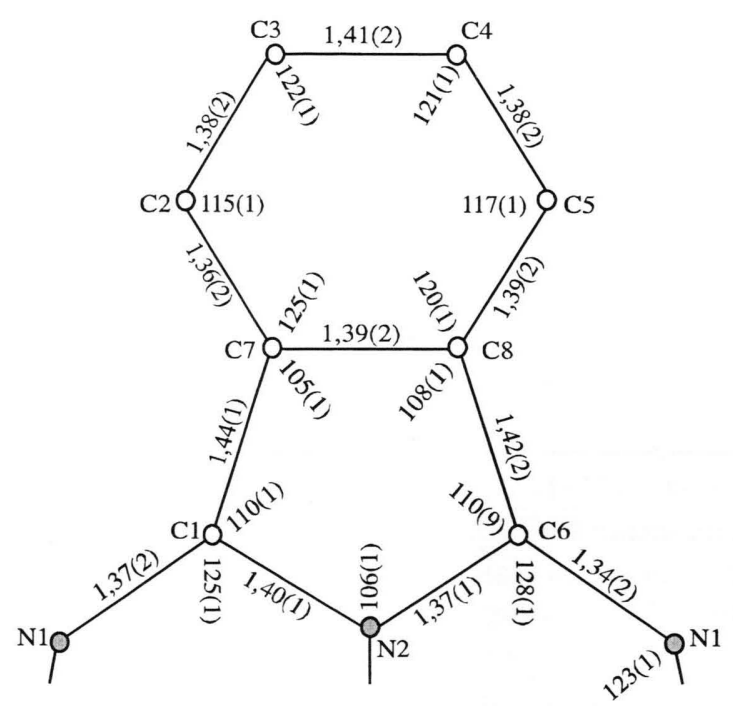

Fig. 3. Atom labeling scheme, inner bond lengths and angles for the asymmetric unit.

\section{Electronic absorption spectra}

Selected absorption spectra are compiled in Fig. 4 and 5. The spectra of $\left[\mathrm{Ce}\left(\mathrm{Pc}^{2-}\right)_{2}\right]$ (4a), $\left[\mathrm{Ce}(\mathrm{Pc})_{2}\right]\left(\mathrm{BF}_{4}\right)_{0.33}(4 \mathrm{~b})$ and $\left[\mathrm{Ce}(\mathrm{Pc})_{2}\right]\left(\mathrm{NO}_{3}\right)(4 \mathrm{c})$ are dominated by the typical intense bands of the $\mathrm{Pc}^{2-}$ ligand at $\mathrm{ca} \cdot 15,000 \mathrm{~cm}^{-1}$ (B band), 30,000 $\mathrm{cm}^{-1}$ ( $\mathrm{Q}$ region) and $36,000 \mathrm{~cm}^{-1}$ ( $\mathrm{N}$ region). For di(phthalocyaninato)cerium(IV) and the tetrafluoroborate salt the $\mathrm{B}$ band absorption $\left(\mathrm{a}_{1 \mathrm{u}} \rightarrow \mathrm{e}_{\mathrm{g}}\right.$; designation following [26]) shows the considerably broadened and poorly structured shape as well as the band splitting characteristic for exciton coupling between dimeric co-facial $\mathrm{Pc}^{2-}$ complexes $[27,28]$. The low energy ("metallic") band at $c a$. 


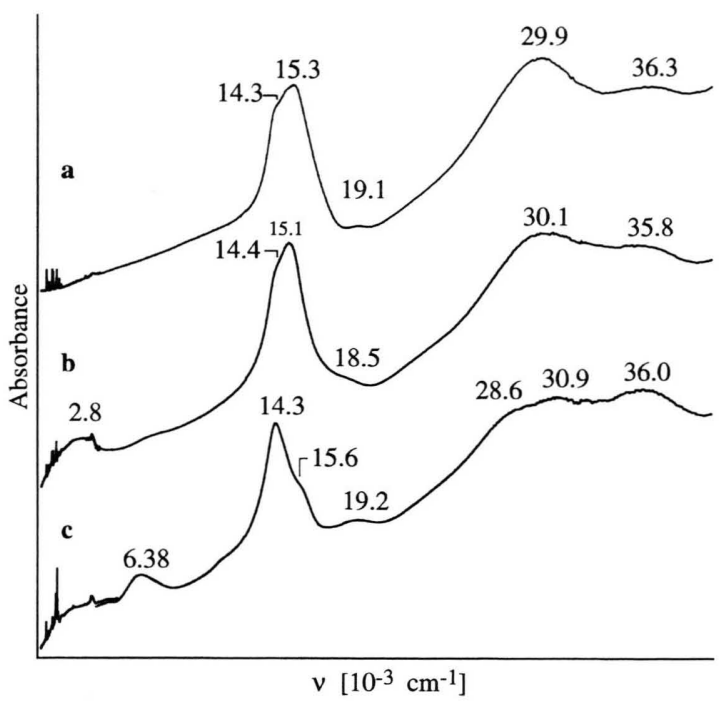

Fig. 4. UV-VIS-NIR-MIR spectra $\left(400-40,000 \mathrm{~cm}^{-1}\right.$, $293 \mathrm{~K}, \mathrm{KBr}$ disks) of $\left[\mathrm{Ce}\left(\mathrm{Pc}^{2-}\right)_{2}\right](\mathrm{a}),\left[\mathrm{Ce}(\mathrm{Pc})_{2}\right]\left(\mathrm{BF}_{4}\right)_{0.33}$ (b) and $\left[\mathrm{Ce}(\mathrm{Pc})_{2}\right]\left(\mathrm{NO}_{3}\right)(\mathrm{c})$.

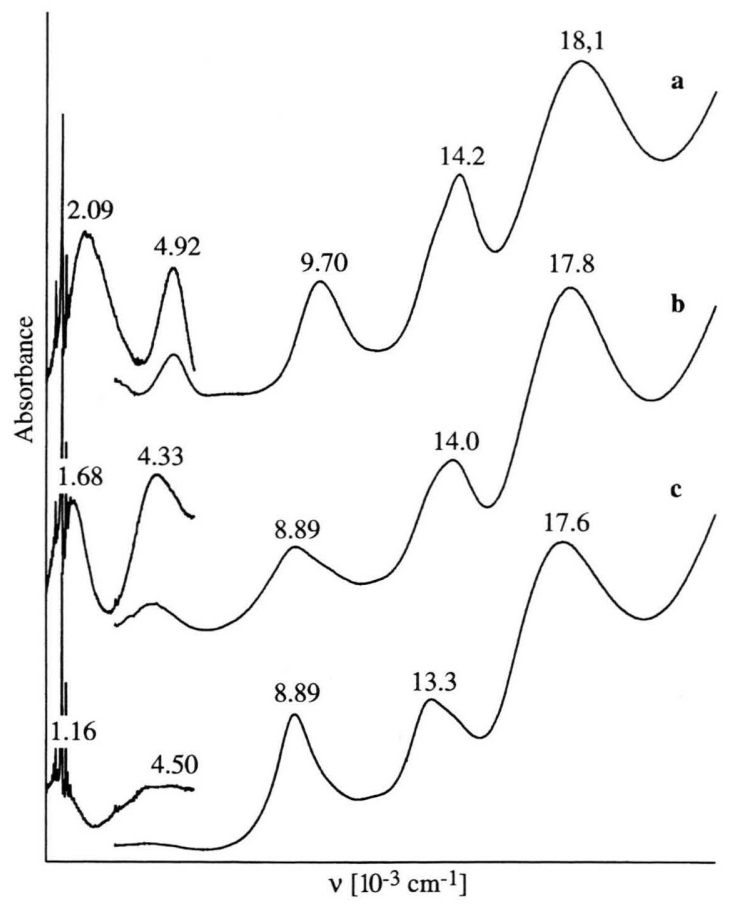

Fig. 5. VIS-NIR spectra $\left(800-22,500 \mathrm{~cm}^{-1}, 293 \mathrm{~K}\right.$, thin film on $\mathrm{CaF}_{2}$ disk) of (PNP) $\left[\mathrm{Ce}\left(\mathrm{Pc}^{2-}\right)_{2}\right]$ after oxidation with $\mathrm{Br}_{2} / \mathrm{N}_{2}$ gas: (a) $5 \mathrm{~s}$, (b) $30 \mathrm{~s}$, (c) $1 \mathrm{~min}$.

$2800 \mathrm{~cm}^{-1}$ in the spectrum of $\left[\mathrm{Ce}(\mathrm{Pc})_{2}\right]\left(\mathrm{BF}_{4}\right)_{0.33}$ is typical for partially oxidized phthalocyanines and has been reported for several other uncompletely oxidized lanthanide(III) [21,22], titanum(IV) and tin(IV) [25] diphthalocyanines and for lithium phthalocyanines [29], showing high electrical conductivities. Therefore it may be assigned to electron phonon coupling.

The $\mathrm{B}$ band of half oxidized $\left[\mathrm{Ce}(\mathrm{Pc})_{2}\right]\left(\mathrm{NO}_{3}\right)$ exhibits a significantly smaller bandwidth with a vibronic transition at $15,600 \mathrm{~cm}^{-1}$ comparable to the analogous complex $\left[\mathrm{La}^{\mathrm{III}}(\mathrm{Pc})_{2}\right]$ [9]. The presence of the $\mathrm{Pc}^{-}$radical is evident from the weak absorption at $c a \cdot 19,200 \mathrm{~cm}^{-1}$, which is assigned to the $\mathrm{Q}_{1}$ transition $\left(\mathrm{a}_{2 \mathrm{u}} \rightarrow \mathrm{e}_{\mathrm{g}}\right)$ of the oxidized macrocycle. Furthermore the NIR band established for "[ $\left.\mathrm{Pc}^{2-} \mathrm{LnPc}^{-}\right]$" compounds [30], is observed at $6380 \mathrm{~cm}^{-1}$. The spectra of $\left[\mathrm{Ce}(\mathrm{Pc})_{2}\right] \mathrm{Cl}_{3.5}$ and $\left[\mathrm{Ce}(\mathrm{Pc})_{2}\right] \mathrm{Br}_{2.7}$ are very similar to that of $\left[\mathrm{Ce}(\mathrm{Pc})_{2}\right]\left(\mathrm{NO}_{3}\right)$ and are not reproduced here. Fig. 5 shows the absorption spectra of purple $\left[\mathrm{Ce}\left(\mathrm{Pc}^{-}\right)_{2}\right] \mathrm{Br}_{x}$. The oxidation of both $\mathrm{Pc}$ ligands is clearly indicated by the intense $\mathrm{Q}_{1}$ and $\mathrm{Q}_{\mathrm{D}}$ bands (designation following ref. 21) at ca. $18,000 \mathrm{~cm}^{-1}$ and $9000 \mathrm{~cm}^{-1}$, respectively, and the low absorbance of the $\mathrm{B}$ band ( $c a$. 14,000 $\mathrm{cm}^{-1}$ ). Additional bands comparable to those observed in the NIR spectra of fully oxidized $\left[\mathrm{Ln}^{\mathrm{III}}\left(\mathrm{Pc}^{-}\right)_{2}\right] \mathrm{Br}_{x}$ occur in the low energy region at $c a .4500 \mathrm{~cm}^{-1}$ and 2000 $\mathrm{cm}^{-1}$. With increasing $\mathrm{Br}_{2}$ contact time $(5 \mathrm{a}-5 \mathrm{c})$ these bands shift to lower wavenumbers and an extreme decrease of intensity takes place. We suggest that these bands arise from very small amounts of less oxidized cerium diphthalocyanines. After still longer $\mathrm{Br}_{2}$ contact the purple film slowly turns green showing a spectrum comparable to that in Fig. 4c. This reduction process is probably caused by traces of moisture.

\section{Vibrational spectra}

The MIR spectra of $\left[\mathrm{Ce}(\mathrm{Pc})_{2}\right] \quad$ (6a), $\left[\mathrm{Ce}(\mathrm{Pc})_{2}\right]\left(\mathrm{BF}_{4}\right)_{0.33}(6 \mathrm{~b}),\left[\mathrm{Ce}(\mathrm{Pc})_{2}\right] \mathrm{Br}_{2.7}(6 \mathrm{c})$ and $\left[\mathrm{Ce}(\mathrm{Pc})_{2}\right]\left(\mathrm{NO}_{3}\right)(6 \mathrm{~d})$ are shown in Fig. 6. Fig. 6a has the characteristic "fingerprint" of the $\mathrm{Pc}^{2-}$ ligand, whereas Fig. $6 c$ is dominated by features of the $\pi$ radical $\mathrm{Pc}^{-}$with the intense bands at $c a .1306$ and $1445 \mathrm{~cm}^{-1}$ and weak absorptions between 1000 and $1200 \mathrm{~cm}^{-1}$. In contrast to the electronic absorption spectra, the contribution of the $\pi$-radical $\mathrm{Pc}^{-}$to the shape of the vibrational spectra is much greater. The band at $1384 \mathrm{~cm}^{-1}$ in the spectrum of $\left[\mathrm{Ce}(\mathrm{Pc})_{2}\right] \mathrm{NO}_{3}$ (Fig. 6d) is due to the 
asymmetric $\mathrm{N}-\mathrm{O}$ stretching vibration $\left(v_{a s}(\mathrm{NO})\right)$ of the nitrate ion. $\left[\mathrm{Ce}(\mathrm{Pc})_{2}\right]\left(\mathrm{BF}_{4}\right)_{0.33}$ exhibits strong $v_{\text {as }}(\mathrm{BF})$ of the tetrafluoroborate at 1075 $\mathrm{cm}^{-1}$. The oxidation of every sixth Pc ligand is verified by the presence of the typical "oxidation bands" mentioned above. The resonance Raman spectra (not shown) closely resemble those of $\left[\mathrm{La}(\mathrm{Pc})_{2}\right][31]$ and are not discussed here in detail. Characteristic bands for the $\mathrm{Pc}^{-}$moiety are centered at $\sim 560 / 1120 / 1172 / 1591 \mathrm{~cm}^{-1}$. It should be mentioned that for $\left[\mathrm{Ce}(\mathrm{Pc})_{2} \mathrm{Br}_{2.5}\right.$ excitation between 457.9 and $476.5 \mathrm{~nm}$ strongly enhances the symmetric stretching vibrations of the polybromide chains at $150 \mathrm{~cm}^{-1}$. In the FT-Raman spectra excited with $1064 \mathrm{~nm}$ the symmetric vibration $\left(v_{\mathrm{s}}\left(\mathrm{Ce}-\mathrm{N}_{\text {iso }}\right)\right)$ at $163 \mathrm{~cm}^{-1}$ is selectively enhanced. For $\left[\mathrm{La}\left(\mathrm{Pc}^{-}\right)_{2}\right] \mathrm{Br}_{2.2}$ and $\left[\operatorname{Pr}\left(\mathrm{Pc}^{-}\right)_{2}\right] \mathrm{Br}_{2.1}$ $v_{\mathrm{s}}\left(\mathrm{Ln}-\mathrm{N}_{\text {iso }}\right)$ is found at 141 and $151 \mathrm{~cm}^{-1}$, for $\left[\mathrm{La}(\mathrm{Pc})_{2}\right]$ and $\left[\operatorname{Pr}(\mathrm{Pc})_{2}\right]$ at 138 and $148 \mathrm{~cm}^{-1}$, respectively. The significantly higher value of $v_{\mathrm{s}}\left(\mathrm{Ce}-\mathrm{N}_{\text {iso }}\right)$ is due to the higher formal oxidation state and the smaller $\mathrm{Ce}^{\mathrm{IV}}$ ionic radius.

\section{Acknowledgement}

We greatfully acknowledge the very valuable support by Prof. Dr. P. Fulde (MPI für Physik komplexer Systeme, Dresden).

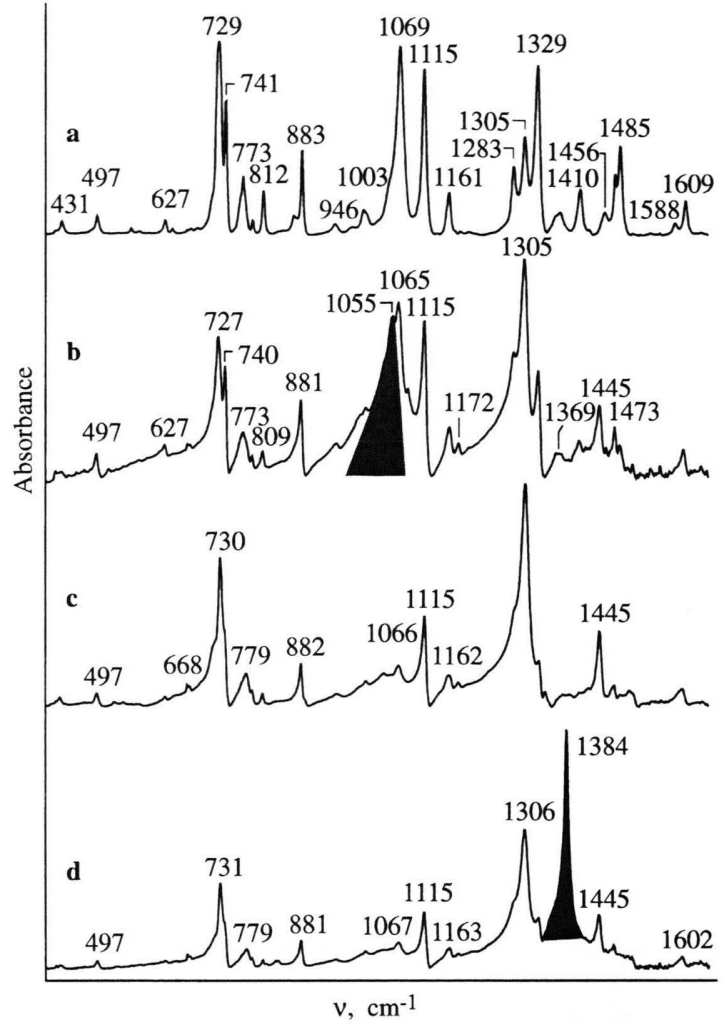

Fig. 6. MIR spectra $\left(400-1650 \mathrm{~cm}^{-1}, 293 \mathrm{~K}\right.$; b-d baseline corrected) of $\left[\mathrm{Ce}\left(\mathrm{Pc}^{2-}\right)_{2}\right]$ (a), $\left[\mathrm{Ce}(\mathrm{Pc})_{2}\right]\left(\mathrm{BF}_{4}\right)_{0.33}$ (b), $\left[\mathrm{Ce}(\mathrm{Pc})_{2} \mathrm{Br}_{2.7}(\mathrm{c})\right.$ and $\left[\mathrm{Ce}(\mathrm{Pc})_{2}\right] \mathrm{NO}_{3}(\mathrm{~d})$.
[1] T. J. Marks, Angew. Chem. 102, 886 (1990); Angew. Chem., Int. Ed. Engl. 102, 857 (1990).

[2] J. Simon, P. Bassoul, in C. C. Leznoff, A. B. P. Lever (eds): Phthalocyanines; Properties and Applications, Vol. 2, p. 227, VCH Weinheim (1993).

[3] S. Besbes, V. Plichon, J. Simon, J. Vaxiviere, J. Electroanal. Chem. Interfacial Electrochem. 237, 61 (1987).

[4] M. M. Nicholson, in C. C. Leznoff, A. B. P. Lever (eds): Phthalocyanines; Properties and Applications, Vol. 3, p. 75, VCH Weinheim (1993).

[5] M. Safarpour Haghighi, Chr.-L. Teske, H. Homborg, Z. Anorg. Allg. Chem. 602, 73 (1992).

[6] M. Dolg, P. Fulde, H. Stoll, H. Preuss, A. Chang, R. M. Pitzer, Chem. Phys., submitted.

[7] M. Dolg, H. Stoll, personal communication.

[8] A. DeCian, M. Moussavi, J. Fischer, R. Weiss, Inorg. Chem. 24, 3162 (1985).
[9] G. Ostendorp, H. Homborg, Z. Naturforsch. 50b, 1200 (1995).

[10] R. J. Donohoe, J. K. Duchowski, D. F. Bocian, J. Am. Chem. Soc. 110, 6119 (1988).

[11] M. Lachkar, A. DeCian, J. Fischer, R. Weiss, New J. Chem. 12, 729 (1988).

[12] J. W. Buchler, A. DeCian, J. Fischer, P. Hammerschmitt, J. Löffler, B. Scharbert, R. Weiss, Chem. Ber. 122, 2219 (1989).

[13] M. Safarpour Haghighi, H. Homborg, Z. Anorg. Allg. Chem. 620, 1278 (1994).

[14] G. Ostendorp, Dissertation Kiel (1995).

[15] G. M. Sheldrick, SHELXS86 Program for Crystal Structure Solution. Univ. of Göttingen, Germany (1990).

[16] G. M. Sheldrick, SHELXL93 Program for the Refinement of Crystal Structures. Univ. of Göttingen, Germany (1993). 
[17] Further details of the crystal structure investigation are available on request from the Fachinformationszentrum Karlsruhe GmbH, D-76344 EggensteinLeopoldshafen, Germany, on quoting the depository number CSD 404625 .

[18] C. K. Johnson, ORTEPII. Report ORLN-5138. Oak Ridge National Laboratory, Tennessee, U.S.A.

[19] H. Konami, M. Hatano, N. Kobayashi, T. Osa, Chem. Phys. Letters 165, 397 (1990).

[20] L. G. Tamilova, N. A. Ovchinnikova, E. A. Luk'yanets, Zh. Obshch. Khim. 57, 2100 (1987).

[21] G. Ostendorp, H. W. Rotter, H. Homborg, Z. Anorg. Allg. Chem., in press.

[22] M. Safarpour Haghighi, M. Rath, H. W. Rotter, H. Homborg, Z. Anorg. Allg. Chem. 619, 1887 (1993).

[23] W. E. Bennett, D. E. Broberg, N. C. Baezinger, Inorg. Chem. 12, 930 (1973).
[24] J. Silver, P. Luekes, S. D. Howe, B. Howlin, J. Mater. Chem. 1, 33 (1991).

[25] A. Capobianchi, C. Ercolani, A. M. Paoletti, G. Pennesi, G. Rossi, A. Chiesi-Villa, C. Rizzoli, Inorg. Chem. 32, 4605 (1993).

[26] H. C. Longuet-Higgins, C. W. Rector, J. R. Platt, J. Phys. Chem. 18, 1174 (1950).

[27] S. Sievertsen, H. Homborg, Z. Anorg. Allg. Chem. 620, 1601 (1994).

[28] N. Kobayashi, A. B. P. Lever, J. Am. Chem. Soc. 109, 7433 (1987).

[29] H. Homborg, Chr. L. Teske, Z. Anorg. Allg. Chem. 527, 45 (1985).

[30] D. Markovitsi, T.-H. Tran-Thi, R. Even, J. Simon, Chem. Phys. Lett. 137, 107 (1987). 